\title{
SISTEM PAKAR EMOSI WANITA JAWA MENGGUNAKAN METODE CERTAINTY FACTOR
}

\author{
Ulla Delfana Rosiani ${ }^{1}$, Twisty Henras Permatasari², Yoppy Yunhasnawa ${ }^{3}$ \\ ${ }^{1,2,3}$ Program Studi Teknik Informatika, Jurusan Teknologi Informasi, Politeknik Negeri Malang \\ ${ }^{1}$ ullarosi@gmail,com , ${ }^{2}$ twistyhenras157@gmail.com, ${ }^{3}$ yunhusnawa@gmail.com
}

\begin{abstract}
Abstrak
Sistem pakar yang merupakan bagian dari kecerdasan buatan adalah sistem komputer yang mampu menirukan penalaran seorang pakar dengan keahlian tertentu. Sistem pakar yang berupa perangkat lunak dapat menggantikan peran seorang pakar (manusia) dalam proses pengambilan keputusan berdasarkan gejala-gejala yang disuplai oleh operator. Sampai pada tingkat keyakinan (certainty) tertentu. Pada karya tulis ini dijelaskan sistem pakar emosi wanita Jawa mengenai implementasi sistem pakar dalam studi kasus tingkat emosi wanita Jawa. Faktor penentu yang digunakan dalam proses pengambilan keputusan. Pada sistem ini bergantung pada 2 tipe masukan yang pertama adalah pertanyaan yang diberikan kepada responden terkait dengan aspek suami, anak, orang tua, saudara dan pekerjaan mereka sedangkan faktor yang kedua adalah nilai-nilai CF pakar yang didapat dari seorang pakar. Pada akhirnya, nilai yang didapat dari kedua faktor tersebut akan diproses menggunakan rumus certainty factor. Sistem yang dibuat hanya dapat digunakan oleh wanita Jawa. User harus memberikan jawaban dari semua pertanyaan yang diberikan oleh sistem. Setelah semua pertanyaan dijawab, sistem akan menampilkan hasil nilai untuk mengidentifikasi bahwa user tersebut mempunyai tingkat emosi tidak pemarah, agak pemarah, cukup pemarah, pemarah, atau sangat pemarah. Selanjutnya sistem akan memberi saran yang sesuai dengan tingkat emosi user. Tingkat keakurasian yang didapatkan pada sistem ini adalah $100 \%$.
\end{abstract}

Kata kunci : sistem pakar, emosi wanita jawa, certainty factor.

\section{Pendahuluan}

\subsection{Latar Belakang}

Emosi merupakan salah satu aspek berpengaruh besar terhadap sikap manusia. Emosi pada prinsipnya menggambarkan perasaan manusia menghadapi berbagai situasi yang berbeda. Emosi adalah pengalaman yang efektif yang disertai oleh penyesuaian batin secara menyeluruh, di mana keadaan mental dan fisiologi sedang dalam kondisi yang meluap-luap, juga dapat diperlihatkan dengan tingkah laku yang jelas dan nyata(Djaali, 2012). Emosi adalah keadaan perasaan yang kompleks yang mengandung komponen kejiwaan, badan, dan perilaku yang berkaitan dengan affect dan $\operatorname{mood}($ Djaali, 2012). Berbicara tentang emosi, wanita lebih emosional dan penuh perasaan sedangkan lakilaki lebih rasional dan menggunakan logika(Pressman, 2002). Kematangan emosi tertinggi pada wanita berusia 24 tahun(Khairani, 2009). Hal ini dapat dijelaskan bahwa bertambahnya usia seseorang menyebabkan emosinya akan semakin terkontrol dan matang(Khairani, 2009).

Wanita Jawa berusaha untuk mencegah munculnya emosi-emosi kuat dalam dirinya. Memperlihatkan perasaan-perasaan spontan dianggap kurang pantas. Menurut Christina S.
Handayani \& Ardhian Novianto (2004) pembawaan diri wanita jawa akan selalu tampak tenang dan terkendali. Nilai Jawa mengandung banyak konsep wanita sejati. Hal ini juga tertulis di berbagai sastra Jawa dalam bentuk serat (buku sastra), cerita wayang, dan juga pada sastra Jawa modern. Konsep perempuan Jawa yang ditulis pada Serat Candrarini (Rosiani, 2015)dapat diklasifikasikan ke dalam 9 item: 1) setia pada suami, 2) kesediaan untuk menjadi istri kedua, 3) cinta orang lain, 4) mempunyai keahlian dalam pekerjaan wanita, 5) baik dalam berpakaian, 6) sederhana, 7) baik dalam melayani sesama, 8) memperhatikan orang tua, 9) suka membaca buku kebijaksanaan. Menurut pakar emosi pada wanita jawa dipengaruhi oleh beberapa aspek yaitu aspek hubungan sosial dengan suami, anak, orangtua, saudara dan pekerjaan, jika berkaitan dengan hal-hal tersebut wanita jawa seringkali tidak dapat mengontrol emosinya, sehingga perlu berkonsultasi dengan pakar untuk membantu wanita jawa dalam mengontrol emosinya namun minimnya keterbatasan ruang dan waktu ketika harus berkonsultasi dengan seorang ahli (pakar) dalam bidang psikologi dapat menyebabkan kendala bagi wanita jawa untuk mengetahui emosinya.

Berdasarkan uraian tersebut maka dipandang perlu untuk menyediakan sebuah aplikasi sistem pakar yang dapat membantu wanita jawa untuk 
mengetahui emosinya tanpa harus mendatangi pakar. Sistem pakar mencoba mencari solusi seperti yang dilakukan seorang pakar dan dapat memberikan penjelasan terhadap langkah yang diambil serta memberikan saran. Dengan aplikasi sistem pakar diharapkan wanita jawa dapat mengetahui emosinya dan memperoleh saran dari pakar sehingga wanita jawa tersebut dapat mengontrol emosinya.

\subsection{Rumusan Masalah}

Berdasarkan latar belakang yang telah dikemukakan, maka dapat dirumuskan permasalahan yaitu: Bagaimana membangun sebuah aplikasi sistem pakar yang dapat memberikan informasi mengenai tingkat emosi kemarahan antara lain tidak pemarah, agak pemarah, atau sangat pemarah serta memberikan saran yang tepat kepada wanita jawa dengan menggunakan metode certainty factor.

\subsection{Batasan Masalah}

Batasan masalah yang diangkat dalam proposal skripsi ini dapat dipaparkan sebagai berikut :

a. Sistem mampu menentukan tingkatan emosi pada wanita jawa dan memberi saran melalui proses tanya jawab, pertanyaan dan pilihan jawaban sudah ada dalam sistem.

b. Berdasarkan penelitian sebelumnya, pada umumnya wanita menikah pada umur 20 tahun sehingga pada sistem pakar ini penggunanya dibatasi hanya untuk wanita berumur 20 tahun keatas, mempunyai anak dan sudah menikah.

c. Parameter aplikasi untuk menentukan tingkatan emosi berdasarkan 40 pertanyaan yang berkaitan dengan 5 topik yaitu: topik suami, topik anak, topik orangtua, topik saudara, dan topik pekerjaan yang masing-masing topik berisi 8 pertanyaan.

d. Representasi pengetahuan yang digunakan adalah sistem pakar berbasis aturan dan dalam penalaran atau inferensinya menggunakan metode certainty factor.

e. Penentu keputusan aplikasi sistem pakar oleh pakar psikologi (Dr.H.Adi Atmoko, M.Si).

f. Data yang digunakan dalam penelitian ini berasal dari penelitian Ulla Delfana Rosiani dan Adi Atmoko yaitu berupa kuisioner yang berkaitan dengan respon emosi marah wanita jawa

\section{Landasan Teori}

\subsection{Kecerdasan Buatan}

Kecerdasan buatan merupakan salah satu bidang ilmu komputer, yang memanfaatkan penggunaan komputer. Hal ini bertujuan agar komputer dapat berperilaku cerdas seperti manusia. Dalam menirukan tindakan manusia, ilmu komputer harus dapat mengembangkan perangkat lunak dan perangkat keras. Adapun aktifitas manusia yang ditirukan oleh komputer yaitu: penalaran, penglihatan, pembelajaran, pemecahan masalah, pemahaman bahasa alami dan sebagainya. Berdasarkan definisi tersebut, teknologi kecerdasan buatan dapat dipelajari dalam bidang seperti Sistem Pakar (Expert System), Penglihatan komputer (Computer Vision), Pemrosesan Bahasa Alami (Natural Language Processing), Permainan Komputer (Games), logika fuzzy, Jaringan Syaraf Tiruan (Artificial Neural System), Pengenalan Suara (Speech Recognition) dan Robotika (Robotics). Kecerdasan buatan dapat menyelesaikan permasalahan dengan memanfaatkan penggunaan komputer untuk memecahkan masalah. Dengan cara meniru proses penalaran manusia. Menurut Sri Hartati \& Sari Iswanti (2008) teknik kecerdasan buatan yang menirukan proses penalaran manusia adalah sistem pakar.

\subsection{Sistem Pakar}

Sistem pakar (Expert System) merupakan salah satu teknik kecerdasan buatan. Sistem pakar dapat didefinisikan sebagai sistem yang mengadopsi pengetahuan manusia ke komputer. Hal ini bertujuan agar komputer dapat menyelesaikan permasalahan seperti yang biasa dilakukan oleh para ahli. Sebuah sistem pakar yang baik harus dirancang sesuai kerja para ahli dalam menyelesaikan sebuah permasalahan. Sistem pakar dapat membantu aktifitas para ahli sebagai asisten yang berpengalaman(Kusumadewi, 2003).

\subsection{Certainty Factor}

Certainty Factor adalah cara penggabungan kepercayaan (belief) dan ketidakpercayaan (unbelief) dalam suatu bilangan tunggal. Nilai certainty factor diperoleh dari data-data kualitatif yang direpresentasikan sebagai derajat keyakinan.

Dalam sebuah permasalahan sering ditemukan jawaban yang tidak memiliki kepastian (uncertainty). Ketidakpastian tersebut dapat berupa probabilitas tergantung hasil suatu kejadian. Terdapat 2 faktor yang menyebabkan ketidakpastian tersebut yaitu: faktor aturan yang tidak pasti dan faktor jawaban user yang tidak pasti pada pertanyaan yang diajukan oleh sistem. Hal ini dapat dilihat sebagai contoh pada sistem diagnosis penyakit. Seorang pakar tidak dapat mendefinisikan dengan pasti hubungan antara gejala dengan penyebab. Selain itu pasien juga tidak dapat merasakan gejala yang pasti, sehingga menimbulkan banyak kemungkinan diagnosis. Suatu sistem pakar harus dapat bekerja dalam ketidakpastian. Contoh teori yang telah ditemukan untuk menyelesaikan permasalahan ketidakpastian yaitu: probabilitas klasik, probabilitas Bayes, teori Hartley berdasarkan himpunan klasik, teori Shannon berdasarkan pada 
probabilitas, teori Dempster-Shafer, teori fuzzy Zadeh dan faktor kepastian.

Ada 3 penyebab ketidakpastian yaitu aturan tunggal, penyelesaian konflik dan ketidakcocokan antar konskuen dalam aturan. Aturan tunggal yang menyebabkan ketidakpastian disebabkan oleh 3 hal yaitu kesalahan, probabilitas dan kombinasi gejala. Kesalahan terjadi karena ambiguitas, ketidaklengkapan data, kesalahan informasi, ketidakpercayaan terhadap suatu alat, serta adanya bias. Probabilitas disebabkan oleh ketidakmampuan seorang pakar dalam merumuskan aturan dengan pasti. Contohnya seseorang menderita sakit kepala, demam dan bersin-bersin dapat didiagnosis orang tersebut menderita sakit flu, namun bukan berarti jika seseorang mengalami gejala tersebut menderita sakit flu. Hanya karena salah satu dari aturannya benar, belum tentu menjamin jawaban bernilai benar. Hal ini karena dipengaruhi oleh kompatibilitas antar aturan. Adapun aturan inkompatibilitas disebabkan oleh beberapa hal yaitu:

a. Kontradiksi aturan

Aturan 1 : jika anak demam maka harus dikompres

Aturan 2 : jika anak demam maka jangan dikompres

b. Subsumpsi aturan

Aturan 3 : jika E1 maka $\mathrm{H}$

Aturan 4 : jika E1 dan E2 maka $\mathrm{H}$

Jika hanya E1 yang muncul, maka masalah tidak akan timbul karena aturan yang akan digunakan adalah aturan 3 tetapi apabila E1 dan E2 samasama muncul maka kedua aturan ( aturan 3 dan 4) sama-sama akan dijalankan.

c. Redundancy aturan

Aturan 5 : jika E1 dan E2 maka $\mathrm{H}$

Aturan 6 : jika E2 dan E1 maka $\mathrm{H}$

Dalam kasus ini ditemui aturan-aturan yang sepertinya berbeda tetapi memiliki makna yang sama.

d. Kehilangan aturan

Aturan 7 : jika E4 maka $\mathrm{H}$

Ketika E4 diabaikan maka $\mathrm{H}$ tidak pernah tersimpulkan

e. Penggabungan data contohnya pada diagnosis kesehatan. Seorang dokter dapat menyimpulkan suatu penyakit tidak hanya berdasarkan anamnesis, tetapi juga berdasarkan hasil tes laboratorium, pemeriksaan kondisi tubuh, sejarah penyakit, dan lain-lain. Untuk itu diperlukan penggabungan semua data untuk dapat menyimpulkan suatu penyakit.

Pemilihan metode penyelesaian konflik mempengaruhi hasil penyelesaian akhir terhadap suatu masalah. Terdapat suatu sistem yang mendahulukan aturan yang lebih spesifik, contohnya aturan 3 dan aturan 4, karena aturan 4 lebih spesifik maka aturan 4 akan dieksekusi dahulu selain itu terdapat sistem yang mengeksekusi aturan berdasarkan urutan pemasukan aturan. Dan terdapat sistem yang memberi bobot pada aturannya sehingga eksekusi dilakukan terhadap aturan berdasarkan bobot yang dimiliki.

Dua model yang digunakan untuk menghitung tingkat keyakinan (CF) dari sebuah rule sebagai berikut

a. Certainty Factor diperkenalkan oleh Shortliffe Buchanan dalam pembuatan MYCIN (Wesley 1984). CF adalah nilai parameter klinis yang diberikan MYCIN yang menunjukkan besarnya kepercayaan.

Certainty factor didefinisikan sebagai berikut

$\mathrm{CF}(\mathrm{HE})=\mathrm{MB}(\mathrm{H}, \mathrm{E})-\mathrm{MD}(\mathrm{H}, \mathrm{E})$

$\mathrm{CF}(\mathrm{H} \mid \mathrm{E})=$ Certainty factor dari hipotesis $\mathrm{H}$ yang dipengaruhi oleh evidence E, besarnya CF berkisar antara -

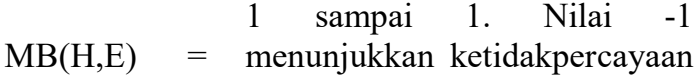
mutlak sedangkan nilai 1

$\operatorname{MD}(\mathrm{H}, \mathrm{E})=$ menunjukkan kepercayaan mutlak.

Ukuran kenaikan kepercayaan terhadap hipotesis $\mathrm{H}$ dipengaruhi oleh gejala E.

Ukuran kenaikan ketidakpercayaan terhadap hipotesis $\mathrm{H}$ dipengaruhi oleh gejala E.

b. Dengan menggali hasil dari penelitian pakar. Nilai CF didapat dari interpretasi term dari pakar menjadi nilai $\mathrm{CF}$ tertentu.

\section{Metodologi}

\subsection{Desain Penelitian}

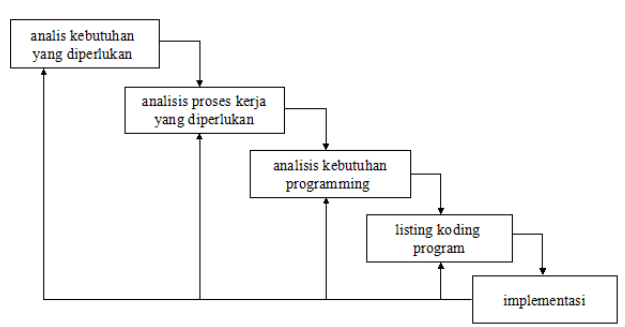

Gambar 1. Digram alur waterfall

4. Perancangan

4.1 Contoh Kasus

Tabel 1. CF Pakar

\begin{tabular}{|c|c|}
\hline Aspek & Nilai CF \\
\hline Suami & 0,6 \\
\hline Anak & 0,6 \\
\hline Orangtua & 0,5 \\
\hline Saudara & 0,7 \\
\hline pekerjaan & 0,6 \\
\hline
\end{tabular}


Tabel 2. Aturan nilai CF dan tingkat emosi wanita jawa

\begin{tabular}{|c|c|}
\hline Aturan & Range \\
\hline Tidak pemarah & $0,47-0,75$ \\
\hline Agak pemarah & $0,76-0,90$ \\
\hline Sangat pemarah & $0,91-0,99$ \\
\hline
\end{tabular}

Tabel 3. Jawaban user

\begin{tabular}{|l|c|c|c|c|c|}
\hline \multirow{2}{*}{ Aspek } & \multicolumn{5}{|c|}{ Respon } \\
\cline { 2 - 6 } & TM & SM & AM & M & MS \\
\hline suami & 2 & 2 & 2 & 1 & 1 \\
\hline anak & 3 & 1 & 1 & 1 & 2 \\
\hline orangtua & 4 & 1 & 1 & 1 & 1 \\
\hline saudara & 1 & 1 & 1 & 2 & 3 \\
\hline pekerjaan & 2 & 3 & 0 & 1 & 2 \\
\hline
\end{tabular}

Keterangan :

$\mathrm{TM}=$ tidak marah

$\mathrm{SM}=$ sedikit marah

$\mathrm{AM}=$ agak marah

$\mathrm{M}=$ marah

MS = sangat marah

Setelah user menginputkan jawaban, seperti diatas sebagai contoh pada pertanyaan aspek suami, user menjawab pertanyaan dengan respon tidak marah sebanyak 2, menjawab pertanyaan dengan respon sedikit marah dan agak marah sebanyak 2, menjawab pertanyaan dengan respon marah 1 , dan menjawab pertanyaan dengan respon sangat marah 1. Begitu juga dengan jawaban pada aspek lain bisa dilihat dalam Tabel 3. Jawaban user. Selanjutnya jawaban user dikalikan dengan nilai masing-masing respon jika tidak marah bernilai 1, sedikit marah bernilai 2, agak marah bernilai 3, marah bernilai 4, sangat marah bernilai 5 .

Tabel 4. Jawaban user dikali nilai respon

\begin{tabular}{|c|c|c|c|c|c|c|}
\hline \multirow{2}{*}{ Aspek } & \multicolumn{5}{|c|}{ Respon } & $\sum$ \\
\cline { 2 - 7 } Suami & 2 & 4 & 6 & 4 & 5 & 21 \\
\hline Anak & 3 & 2 & 3 & 4 & 10 & 22 \\
\hline Orangtua & 4 & 2 & 3 & 4 & 5 & 18 \\
\hline Saudara & 1 & 2 & 3 & 8 & 15 & 29 \\
\hline Pekerjaan & 2 & 6 & 0 & 4 & 10 & 22 \\
\hline
\end{tabular}

Keterangan :

$\mathrm{TM}=$ tidak marah

SM $=$ sedikit marah

$\mathrm{AM}=$ agak marah

$\mathrm{M}=$ marah

MS = sangat marah
Dari jawaban user yang sudah dikalikan dengan nilai respon akan menghasilkan jumlah total selanjutnya jumlah total tersebut di bagi dengan 40 untuk mendapatkan nilai CF user. Nilai 40 adalah nilai maksimal yang didapatkan dari nilai respon tertingi yaitu 5 dikalikan dengan jumlah pertanyaan per aspek yaitu 8 sehingga diperoleh nilai maksimal 40.

Tabel 5. Nilai CF user

\begin{tabular}{|c|c|c|}
\hline Aspek & Total & Nilai CF user \\
\hline suami & 21 & 0,525 \\
\hline anak & 22 & 0,55 \\
\hline orangtua & 18 & 0,45 \\
\hline saudara & 29 & 0,725 \\
\hline pekerjaan & 22 & 0,55 \\
\hline
\end{tabular}

Selanjutnya hitung nilai $\mathrm{CF}$ sequensial yaitu perkalian nilai $\mathrm{CF}$ user dengan $\mathrm{CF}$ pakar.

Tabel 6. Nilai CF Sequensial

\begin{tabular}{|c|c|c|c|}
\hline Aspek & $\begin{array}{c}\text { CF } \\
\text { user }\end{array}$ & $\begin{array}{c}\text { CF } \\
\text { pakar }\end{array}$ & $\begin{array}{c}\text { CF } \\
\text { sequensial }\end{array}$ \\
\hline suami & 0,525 & 0,6 & 0,315 \\
\hline anak & 0,55 & 0,6 & 0,33 \\
\hline orangtua & 0,45 & 0,5 & 0,225 \\
\hline saudara & 0,725 & 0,7 & 0,5075 \\
\hline pekerjaan & 0,55 & 0,6 & 0,33 \\
\hline
\end{tabular}

Langkah terakhir yaitu menghitung CF combine atau $\mathrm{CF}$ gabungan yang dihitung dengan persamaan

\section{CFcombine $=$ CFold + CFnew $*(1-$ CFold $)$}

$$
\begin{aligned}
& \mathrm{CF} \text { (A) }=\text { CFold }+ \text { CFnew } * \text { (1-CFold) } \\
& =0,315+0,33 *(1-0,315) \\
& =0,54105 \text { CFold } \\
& \mathrm{CF}(\mathrm{B})=\text { CFold }+ \text { CFnew * (1-CFold) } \\
& =0,54105+0,225 *(1-0,54105) \\
& =0,64431375 \text { CFold } \\
& \mathrm{CF}(\mathrm{C})=\text { CFold }+ \text { CFnew * (1-CFold) } \\
& =0,64431375+0,5075 *(1-0,64431375) \\
& =0,824824522 \text { CFold } \\
& \mathrm{CF} \text { (D) }=\text { CFold }+ \text { CFnew * (1-CFold) } \\
& =0,824824522+0,33 *(1-0,824824522) \\
& =0,88263243
\end{aligned}
$$

Dari perhitungan secara manual di atas, diperoleh nilai CF yang merujuk ke emosi wanita jawa adalah 
0,88. Menurut Tabel Aturan nilai CF dan Tingkat emosi wanita jawa hal ini menunjukkan bahwa user memiliki tingkat emosi sangat pemarah.

\section{Implementasi}

\subsection{Alur Sistem}

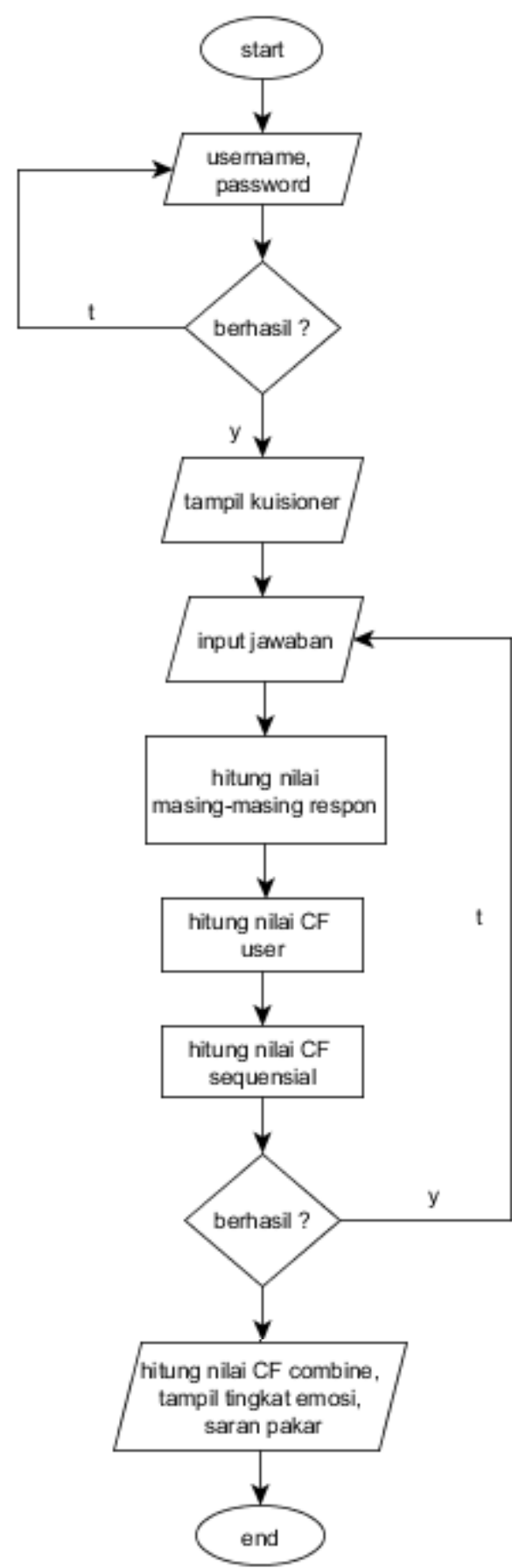

Gambar 2. Alur Sistem

Pada gambar 2 terdapat tahapan untuk memulai konsultasi. pertama user harus melakukan login terlebih dahulu dengan username dan password, jika username dan password sesuai maka sistem akan menampilkan halaman kuisioner, setelah itu user dapat menginput jawaban dengan memilih jawaban yang sudah disiapkan oleh sistem.
Selanjutnya jawaban user diproses untuk mengetahui nilai masing-masing respon, dari nilai masing-masing respon tersebut akan diolah oleh sistem sehingga menghasilkan nilai CF user, setelah itu sistem akan memproses nilai $\mathrm{CF}$ user dengan metode certainty factor untuk mendapatkan $\mathrm{CF}$ sequensial, selanjutnya hasil dari CF sequensial akan digunakan untuk menghitung $\mathrm{CF}$ combine yang akan menghasilkan nilai respon emosi pada jawaban user serta saran untuk user.

\subsection{Tampilan Kuisioner}

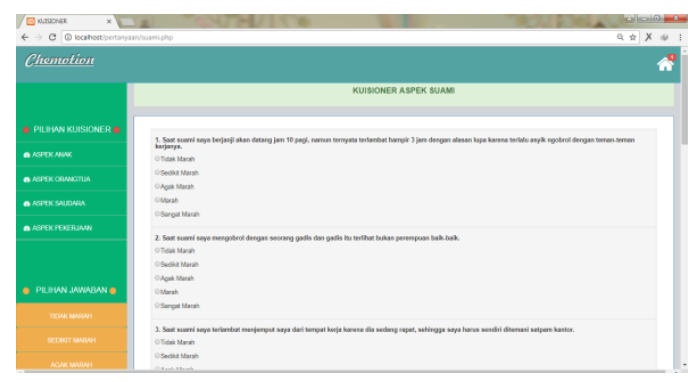

Gambar 3. Tampilan kuisioner aspek suami

\subsection{Tampilan Hasil Konsultasi}

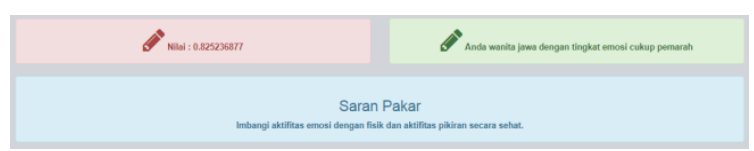

Gambar 4. Tampilan hasil konsultasi

\section{Kesimpulan Dan Saran}

\subsection{Kesimpulan}

Adapun kesimpulan yang dapat diambil dari hasil penelitian yang dilakukan mengenai Sistem Pakar Emosi Wanita Jawa sebagai berikut.

a. Metode Certainty Factor dapat diterapkan pada suatu sistem pakar yang mengidentifikasi emosi pada wanita jawa berdasarkan beberapa fakta yang berasal dari pakar dan input dari user pada saat user mengisi kuisioner.

b. Hasil identifikasi tingkat emosi dipengaruhi oleh nilai yang berasal dari jawaban user. Selain itu tingkat emosi juga mempengaruhi pemberian saran dari pakar.

c. Sistem yang dibuat dapat mendeteksi tingkat emosi seseorang berdasarkan jawaban yang di pilih user pada saat menjawab pertanyaan.

d. Tingkat keakurasian sistem pakar emosi wanita jawa menggunakan metode Certainty Factor adalah $100 \%$. Data ini didapatkan dari pengujian 10 sampel data.

\subsection{Saran}

Berdasarkan penelitian, ada beberapa hal yang disarankan antara lain sebagai berikut.

a. Diharapkan sistem ini dapat dilakukan penambahan fitur untuk pakar agar pakar dapat mengelola data kuisioner yang berikan kepada 
sistem, sehingga aplikasi yang dibuat dapat lebih lengkap.

b. Sebaiknya untuk penelitian lebih lanjut dapat lebih digali ciri-ciri marah serta penyebab emosi wanita Jawa, sehingga aplikasi yang dibuat dapat mengidentifikasi tingkat emosi dengan lebih dalam.

\section{Daftar Pustaka :}

Hasibuan Adlin 2014. "Sistem Pakar Diagnosa Kecanduan Menggunakan Internet (Internet Addiction) Menggunakan Metode Certainty Factor". STMIK Budidarma Medan.

Betha, Sidik 2001. "Pemrograman Web dengan PHP". Bandung : Informatika.

Handayani Christina S, Novianto Ardhian 2004. "Kuasa Wanita Jawa", PT LKiS Pelangi Aksara

Djaali, "Psikologi Pendidikan". 2012 Cetakan 6. Jakarta : PT Bumi Aksara.

Greenberg, L.S \& Watson, J.C 2006. "EmotionFocuced Therapy for Depression". Washington DC:American Psychologikal Association.

Hartati Sri dan Iswanti Sari 2008. "Sistem Pakar dan Pengembangannya”. Yogyakarta : Graha Ilmu.
Kusumadewi Sri 2003. "Artificial Intelligence (Teknik dan Aplikasinya)”, Graha Ilmu. Yogyakarta

Khairani, Rahma, Putri Dona Eka 2009. "Perbedaan Kematangan Emosi Pada Pria dan Wanita". Fakultas Psikologi, Universitas Gunadarma

Susanti Rita, Desma Husni, Eka Fitriyani 2014. “Perasaan Terluka Membuat Marah". Fakultas Psikologi Universitas Islam Negeri Sultan Syarif Kasim Riau, 2014.

Pressman Roger S 2002. "Rekayasa Perangkat Lunak Pendekatan Praktisi (Buku Satu)”, ANDI Yogyakarta.

Santrock, J.W 2009. "Psikologi Pendidikan. Educational Psychology" (terj. Diana Angelica). Jakarta: Penerbit Salemba Humanika.

Sutojo, T., Mulyanto, E., \& Suhartono 2011, “ Kecerdasan Buatan”, Yogyakarta: Andi.

Turban, E. and Aronson, J. E 2001. "Decision Support and Intelegent Systems", (6 th ed.) Prentice-Hall Inc, New Jersey.

Rosiani Ulla Delfana 2015. "The Synthesis of Javanese Woman's Facial Image on Anger Expression Based on Emotion Regulation", Institut Teknologi Sepuluh November, Surabaya, Indonesia. 